\title{
O FORTALECIMENTO DA IDENTIDADE NEGRA NA EDUCAÇÃO SUPERIOR: entre a negação e o reconhecimento
}

\author{
THE STRENGTHENING OF BLACK IDENTITY IN HIGHER EDUCATION: \\ between refusal and recognition
}

Eugenia Portela de Siqueira Marques ${ }^{1}$ Maria Aparecida Pereira dos Santos Ribeiro ${ }^{2}$

\section{Resumo}

O objetivo desse artigo é discutir as possibilidades de os acadêmicos negros, ingressantes pelas cotas raciais nos cursos de graduação presencial da Universidade Federal da Grande Dourados, fortalecerem a identidade, considerando-se que o espaço acadêmico e a cultura universitária estão marcados pelo eurocentrismo, pelos estereótipos e pelo preconceito. Delimitou-se como questão norteadora: em que medida o acesso e a permanência na educação superior poderão fortalecer a identidade dos sujeitos negros ingressantes pelas cotas raciais na Universidade Federal da Grande Dourados? Trata-se de resultados de pesquisa realizada no âmbito do Mestrado em Educação. Optou-se pela pesquisa bibliográfica, análise documental e pesquisa de campo. Foram utilizados como instrumentos o questionário on-line e a entrevista estruturada. Foram entrevistados seis acadêmicos negros cotistas de diferentes cursos ingressantes no período de 2013 a 2016. Para a contextualização histórica, apresentamos discussões sobre a importância do Movimento Negro, a implantação das ações afirmativas as possibilidades de fortalecimento da identidade negra. Os resultados mostraram que todas as situações de discriminação e preconceito que estão presentes na sociedade brasileira, constantemente denunciadas pelo Movimento Negro, estão presentes no espaço acadêmico de forma direta ou indireta.

Palavras-chave: Identidade negra. Educação superior. Movimento negro.

\section{Abstract}

The online questionnaire and the structured The objective of this article is to discuss the possibilities of black academics entering racial quotas in the undergraduate courses of the Federal University of Grande Dourados, to

\footnotetext{
${ }^{1}$ A autora é doutora em Educação pela UFSCAR. É docente do PPGEDU da Faculdade de Educação, e pesquisadora da Diversidade étnico-racial, currículo e política afirmativa. E-mail: eumar13@terra.com.br

${ }^{2}$ Mestre em Educação pelo Programa de Pós-graduação em Educação da UFGD. Professora formadora da Coordenadoria Regional de Educação / Gestão Tecnológica de Naviraí - CRE 8. Membro do Grupo de Pesquisa GEPRAFE/UFGD. E-mail: Mpr.2010@hotmail.com
} 
strengthen their identity, considering that academic space and university culture are marked by Eurocentrism, Stereotypes and prejudice. It was delimited as a guiding question: to what extent the access and permanence in higher education could strengthen the identity of the black subjects entering the racial quotas at the Federal University of Grande Dourados? These are results of research carried out under the Master in Education. We opted for bibliographic research, documentary analysis and field researchinterview were used as instruments. We interviewed six black academics from different entry courses from 2013 to 2016 . For historical contextualization, we present discussions about the importance of the Black Movement, the implementation of affirmative actions and the possibilities of strengthening the black identity. The results showed that all situations of discrimination and prejudice that are present in Brazilian society, constantly denounced by the Black Movement, are present in the academic space directly or indirectly.

Key-words: Black identity. Higher education. Black movement.

\section{Introdução}

As reivindicações do Movimento Negro, a luta pela implantação das ações afirmativas, os discursos contrários, as práticas racistas e as visões estereotipadas fazem parte do contexto que constrói a política de identidade que tensiona a sociedade, o currículo monocultural e eurocentrado. A presença dos acadêmicos negros na Universidade pode representar a transgressão do modelo imposto pela cultura acadêmica homogeneizada. Nessa perspectiva, para compreendermos como se dá, hoje, a construção da identidade, é preciso levar em consideração o mito da democracia racial, a descolonização, a implantação das ações afirmativas, o racismo institucional e a desigualdade racial.

O mito da democracia racial no Brasil, conforme Guimarães (2002), teve início em 1937, em Lisboa, na conferência "Aspectos da influência da mestiçagem sobre relações sociais e de cultura entre portugueses e lusodescendentes". Na ocasião, Gilberto Freyre apresentava a democracia racial como um legado da população luso-brasileira. Transmitia, assim, a ideia de que a sociedade brasileira não fazia distinção de cor e que todos tinham as mesmas oportunidades, ou seja, mostrava uma sociedade sem preconceitos e discriminações raciais, que vivia harmoniosamente o encontro das três raças. Carneiro (1995, p. 35-36) pontua que: 
Em vez de ameaça, a mestiçagem foi transformada por Gilberto Freyre em solução para os problemas do Brasil, graças ao legado cultural português. O brasileiro estaria a caminho de produzir uma nova raça através do processo de miscigenação, que [...] possibilitou ao mulato que atendia aos padrões estéticos e eugênicos do senhor branco melhores condições de vida e ascensão social.

Desse modo, o mito da democracia racial maquia a situação real da sociedade brasileira, sinaliza Gomes (2005, p. 57):

O mito da democracia racial pode ser compreendido, então, como uma corrente ideológica que pretende negar a desigualdade racial entre brancos e negros no Brasil como fruto do racismo, afirmando que existe entre estes dois grupos raciais uma situação de igualdade de oportunidade e de tratamento. Esse mito pretende, de um lado, negar a discriminação racial contra os negros no Brasil, e, de outro lado, perpetuar estereótipos, preconceitos e discriminações construídos sobre esse grupo racial. Se seguirmos a lógica desse mito, ou seja, de que todas as raças e/ou etnias existentes no Brasil estão em pé de igualdade sócio-racial e que tiveram as mesmas oportunidades desde o início da formação do Brasil, poderemos ser levados a pensar que as desiguais posições hierárquicas existentes entre elas devem-se a uma incapacidade inerente aos grupos raciais que estão em desvantagem, como os negros e os indigenas. Dessa forma, o mito da democracia racial atua como um campo fértil para a perpetuação de estereótipos sobre os negros, negando o racismo no Brasil, mas, simultaneamente, reforçando as discriminações e desigualdades raciais.

Diante dessa realidade, a atuação do Movimento Negro foi determinante para desmitificar esse mito e, juntamente com os pesquisadores da temática, produzirem resultados de pesquisa que comprovam que a desigualdade racial, o racismo e a discriminação racial influenciaram de forma negativa a construção da identidade negra.

As discussões sobre essas questões passam a ser discutidas com a adoção das politicas afirmativas no Brasil que além de buscar a reparação ou compensação das desigualdades entre negros e brancos, possibilitou o debate o pertencimento étnico-racial e o fortalecimento identitário, com a inserção de negros no espaço acadêmico, historicamente ocupado pela população branca. Nesse sentido, as políticas afirmativas são medidas voltadas para a correção das desigualdades e a garantia de direitos, ou seja, visa a garantir a grupos 
excluídos meios e oportunidade de participação em todos os setores da sociedade. Segundo Jaccoud e Beghin (2002, p. 67), as ações afirmativas são politicas que:

Têm por objetivo garantir a oportunidade de acesso dos grupos discriminados, ampliando sua participação em diferentes setores da vida econômica, política, institucional, cultural e social. Elas se caracterizam por serem temporárias e por ser focalizadas no grupo discriminado; ou seja, por dispensarem, num determinado prazo um tratamento diferenciado e favorável com vistas a reverter um quadro histórico de discriminação e exclusão. Essas ações não são sinônimas de políticas de cotas. Podem, por exemplo, organizar-se na forma de ações específicas de qualificação ou de estabelecimento de metas ao longo do tempo para ampliar a presença de negros em determinados espaços da vida social.

É pertinente ressaltar que as ações afirmativas não se restringem à reserva de vagas por meio do sistema de cotas raciais ou sociais nas universidades, conforme é o entendimento mais comum na sociedade. Elas são politicas públicas ou privadas compulsórias ou não, que têm por objetivo último erradicar da sociedade as práticas discriminatórias dirigidas a determinados grupos sociais, historicamente excluidos e cujo reconhecimento e prestígio social sejam baixos, ou mesmo inexistentes. Ao direito à igualdade foi acrescentado o direito à diferença e à diversidade, cuja proteção advém do princípio da equidade.

\section{Concepções sobre Identidade e o Direito de ser "Diferente"}

A discussão sobre a identidade nos leva a refletir sobre os processos pelos quais o ser humano passa ao longo de sua vida, seja no campo político, cultural ou social. Segundo Hall (2006, p. 13):

O sujeito assume identidades diferentes em diferentes momentos, identidades que não são unificadas ao redor de um 'eu' coerente. Dentro de nós há identidades contraditórias, empurrando em diferentes direções, de tal modo que nossas identificações estão sendo continuamente deslocadas.

Nesse contexto o autor apresenta três concepções de identidade presentes em diferentes momentos históricos. São eles: a) sujeito do 
Iluminismo, em que esse sujeito era considerado um indivíduo totalmente centrado num núcleo interior, que já nascia com ele, se desenvolvia e permanecia até a morte; b) sujeito sociológico, em que se reconhecia o núcleo interior, porém esse núcleo não era autônomo e se modificava pela relação estabelecida com o outro; c) sujeito pós-moderno, em que a identidade desse sujeito não é considerada fixa, essencial ou permanente, isto é, a identidade é formada e transformada continuamente.

O termo identidade carrega em seu bojo dimensões sociais, pessoais e coletivas, à medida que o indivíduo vai se afirmando num determinado grupo, ou seja, a sua identidade vai sendo construída. Sob essa ótica, Gomes (2003, p. 41) considera que:

A identidade não é algo inato. Ela se refere a um modo de ser no mundo e com os outros. É um fator importante na criação das redes de relações e de referências culturais dos grupos sociais. Indica traços culturais que se expressam através de práticas linguísticas, festivas, rituais, comportamentos alimentares e tradições populares referências civilizatórias que marcam a condição humana.

Não sendo a identidade algo fixo, mas algo que está em constante mudança, concordamos com Dayrell (1996, p. 141), que diz que o homem vai se constituindo num processo contínuo, de acordo com as interações vivenciadas ao longo de sua história. Destacamos também o que pontua Hall (2006, p. 13): a identidade "[...] plenamente unificada, completa, segura e coerente é uma fantasia”. Conclui-se, pois, que a construção e o fortalecimento da identidade acontecem por meio das relações entre os sujeitos ao longo de sua vida. Destacamos que essa interação acarretará conflitos identitários que podem influenciar positiva ou negativamente.

Nesse contexto, os estudos culturais consideram o individuo um ser sociável que é influenciado pela história, pela cultura e pela interação. Segundo Hall (2006, p.7), “[...] as velhas identidades, que por tanto tempo estabilizaram o mundo social, estão em declínio, fazendo surgir novas identidades e fragmentando o indivíduo moderno, até aqui visto como um sujeito unificado". 
Embora o econômico seja considerado um dos aspectos que compõem esse processo histórico, o sujeito é influenciado também pelos aspectos culturais. Conforme aponta Santana (2010, p. 99):

[...] os Estudos Culturais nos permitem compreender, esse sujeito é socialmente construído ao longo do processo histórico e, dessa forma, é um sujeito cultural, e a cultura é perpassada por diversos elementos das práticas sociais, e o econômico é apenas um desses elementos constitutivos; por isso se torna reducionista pensar que ele seja o único.

As contribuições de Azibeiro (2003, p. 93) sinalizam que as diferenças culturais traduzem construções histórico-culturais que decorrem da relação de poder, nas quais "[...] os diferentes grupos sociais, particularmente os subalternos, podem redescobrir e reconstruir o valor positivo de suas culturas e experiências específicas, ressignificando-as”. Também Gusmão (2003, p. 91), sinaliza que a cultura não estática “[...] marcada por intensas trocas e muitas contradições nas relações entre grupos culturais diversos e mesmo no interior de um mesmo grupo".

Sendo assim, a construção da identidade se dá pelas relações mantidas com os grupos, em que cada um vai se abrindo e se afirmando positiva ou negativamente. Para Gomes (2003, p.171), “[...] construir a identidade negra positiva em uma sociedade que, historicamente, ensina ao negro, desde muito cedo, que para ser aceito é preciso negar-se a si mesmo, é um desafio enfrentado pelos negros brasileiros".

Refletir sobre a identidade negra requer reconhecer a existência de outros tipos de identidades, principalmente em se tratando do Brasil, um país multicultural e multirracial. Se a construção da identidade é um processo que permeia as relações, são necessários meios para que o sujeito possa construíla, ou seja, ele deve compreender que:

[...] esta identidade passa, em seu processo de construção, pela cor da pele. O que significaria que essa identidade tem a ver com a tomada de consciência da diferença biológica entre 'Brancos' e 'Negros', 'Amarelos' e 'Negros' enquanto grupos. É importante frisar que a negritude, embora tenha sua origem na cor da pele negra, não é essencialmente de ordem biológica. De outro modo, a identidade negra não nasce do simples fato de se tomar 
consciência da diferença de pigmentação entre brancos e negros ou negros e amarelos. A negritude ou a identidade negra se refere à história comum que o olhar do mundo ocidental 'branco' reuniu sob o nome de negros. (MUNANGA, 2012, p. 12).

A história da população negra no Brasil é marcada pela colonialidade, que segundo Mignolo (2003, p. 40), “[...] pressupõe a diferença colonial como sua condição de possibilidade e como aquilo que legitima a subalternização do conhecimento e a subjugação dos povos”. Sobre a herança histórica do eurocentrismo espalhado por toda a América Latina, Quijano (2005, p. 239) considera que:

Aplicada de maneira específica à experiência histórica latinoamericana, a perspectiva eurocêntrica de conhecimento opera como um espelho que distorce o que reflete. Quer dizer, a imagem que encontramos nesse espelho não é de todo quimérica, já que possuímos tantos e tão importantes traços históricos europeus em tantos aspectos, materiais e intersubjetivos. Mas, ao mesmo tempo, somos tão profundamente distintos. Daí que quando olhamos nosso espelho eurocêntrico, a imagem que vemos seja necessariamente parcial e distorcida. Aqui a tragédia é que todos fomos conduzidos, sabendo ou não, querendo ou não, a ver e aceitar aquela imagem como nossa e como pertencente unicamente a nós. Dessa maneira seguimos sendo o que não somos. E como resultado não podemos nunca identificar nossos verdadeiros problemas, muito menos resolvê-los, a não ser de uma maneira parcial e distorcida.

Essa experiência, no Brasil, é herança de um passado escravocrata, e mesmo após a abolição ela permeia as relações sociais, levando o sujeito negro a construir sua identidade em meio a constantes conflitos identitários decorrentes do preconceito, dos estereótipos, dos enfrentamentos advindos da imposição cultural, do modo de ser. As características fenotípicas dos negros, principalmente a cor da pele, o formato do nariz e da boca e a textura dos cabelos sempre foram utilizados para hostilizar e inferiorizar. A esse tipo de preconceito racial Nogueira (2006, p. 292) define que,

O preconceito de raça se exerce em relação à aparência, isto é, quando toma por pretexto para as suas manifestações os traços físicos do individuo, a fisionomia, os gestos, o sotaque, diz-se que é de marca; quando basta a suposição de que o indivíduo 
descende de certo grupo étnico para que sofra as consequências do preconceito, diz-se que é de origem.

Verifica-se, assim, que no Brasil predomina o preconceito de marca, em que as marcas, ou seja, o tipo de cabelo, o formato do nariz, tonalidade da cor são características que tornam uma pessoa mais suscetivel de ser discriminada ou não. Conforme ressalta Gomes (2002, p. 41), “[...] na instituição escolar, assim como na sociedade, nós comunicamos por meio do corpo. Um corpo que é construído biologicamente e simbolicamente na cultura e na história". Na pesquisa "Corpo e cabelo como ícones de construção da beleza e da identidade negra nos salões étnicos de Belo Horizonte”, ao entrevistar mulheres negras, Gomes (2002, p. 41) ressalta que:

[...] várias depoentes, ao se reportarem ao corpo, relembraram momentos significativos da sua história de vida, dando um destaque especial à trajetória escolar. Para essas pessoas, na sua maioria mulheres negras jovens e adultas, na faixa dos 20 aos 60 anos, a experiência com o corpo negro e o cabelo crespo não se reduz ao espaço da família, das amizades, da militância ou dos relacionamentos afetivos. A trajetória escolar aparece em todos os depoimentos como um importante momento no processo de construção da identidade negra e, lamentavelmente, reforçando estereótipos e representações negativas sobre esse segmento étnico/racial e o seu padrão estético.

O exotismo e o esquecimento que estão sendo reproduzidos ao longo do tempo apontaram a cultura negra como primitiva e negativa. Eis a razão pela qual o processo identitário da população negra se torna ainda mais dificil, haja vista que perpassa estigmas históricos em que ela foi inferiorizada e subjugada diante dos valores eurocêntricos.

De acordo com Munanga (2004, p. 110), “o processo de construção dessa identidade brasileira, na cabeça da elite pensante e política, deveria obedecer a uma ideologia hegemônica baseada no ideal do branqueamento". Aqui notamos que essa elite tem arraigados os valores eurocêntricos, e que tudo o que não se enquadra com as suas características é discriminado. E com pensamento se forma a identidade nacional, como sinaliza Munanga (2012, p. 6), “[...] além da identidade nacional brasileira, que reúne a todas e 
todos, estamos atravessados/as por outras identidades de classe, sexo, religião, etnias, gênero, idade, raça, etc., cuja expressão depende do contexto relacional". Verifica-se, assim, que a identidade se constitui pelas interrelações com o outro. Daí a importância da discussão sobre a identidade e a sua construção, já que ela se faz presente em toda sociedade, conforme afirma Munanga (1994, p. 177-178):

A identidade é uma realidade sempre presente em todas as sociedades humanas. Qualquer grupo humano, através do seu sistema axiológico sempre selecionou alguns aspectos pertinentes de sua cultura para definir-se em contraposição ao alheio. A definição de si (auto definição) e a definição dos outros (identidade atribuída) têm funções conhecidas: a defesa da unidade do grupo, a proteção do território contra inimigos externos, as manipulações ideológicas por interesses econômicos, políticos, psicológicos, etc.

A identidade negra perpassa a reflexão sobre o contexto social brasileiro, que historicamente apresenta o negro numa condição inferior em relação ao branco, apontando o estereótipo da condição de escravo ou ligado a situações de subordinação e inferioridade. Compreender essa identidade é entender as relações sociais em que o indivíduo está inserido, como sinaliza Munanga (2004, p. 89):

O mito de democracia racial, baseado na dupla mestiçagem biológica e cultural entre as três raças originárias, tem uma penetração muito profunda na sociedade brasileira: exalta a idéia de convivência harmoniosa entre os indivíduos de todas as camadas sociais e grupos étnicos, permitindo às elites dominantes dissimular as desigualdades e impedindo os membros das comunidades não-brancas de terem consciência dos mecanismos de exclusão da qual são vítimas na sociedade.

Nesse sentido, o mito da democracia racial sempre pregou que todos são iguais, porém a realidade do Brasil é bem diferente - que democracia é essa? Uma democracia em que a colonialidade legitima que brancos são superiores e negros inferiores reflete as desigualdades em todos os setores. A ideologia do branqueamento interferiu na formação da identidade do povo brasileiro e a negação da existência da herança africana na composição dessa identidade. 
Nesse contexto, existem ainda alguns enfrentamentos, de acordo com Santos e Silva (2005, p. 40), “[...] o processo de fortalecimento da identidade racial brasileira é uma possibilidade de enfrentamento da discriminação racial”. Esses enfrentamentos estão ligados ao fenótipo do negro, à sua cultura e às suas condições econômicas.

Entendemos, pois, que é preciso levar em consideração os aspectos sociais, politicos, étnicos, individuais e coletivos que influenciam na construção ou no fortalecimento da identidade de cada pessoa.

A definição de identidade coletiva, de acordo com Munanga (2012, p. 9):

É uma categoria de definição de um grupo. Esta definição pode ser feita pelo próprio grupo através de alguns atributos selecionados no seu complexo cultural (lingua, religião, arte, sistemas político, economia, visão do mundo), de sua história, de seus traços psicológicos letivos, etc., entendidos como mais significativos do que outros e que o diferenciam de demais grupos ou comunidades, religiões, nações, etnias, etc. O que 'nós', antropólogos, chamamos de sinais diacríticos. Trata-se aqui da identidade como categoria de autodefinição ou autoatribuição, que sem dúvida carrega uma carga de subjetividade e de preconceitos em relação aos outros grupos.

Dentro da categoria autodefinição, o autor declara que o primeiro fator constitutivo dessa identidade é a história. Mas se “[...] a história é fator principal, como construir essa identidade se mal a conhecemos, uma vez que ela foi contada do ponto de vista do 'outro', de maneira depreciativa e negativa”. (MUNANGA, 2012, p. 9).

É, portanto, fundamental para a população negra reencontrar o fio condutor da verdadeira história do negro que o liga à África, sem distorções nem falsificações, para, assim, ela ir se apropriando de sua história. Conforme Munanga (2012, p. 10) assinala:

[...] no processo de construção da identidade coletiva negra, é preciso resgatar sua história e autenticidade, desconstruindo a memória de uma história negativa que se encontra na historiografia colonial ainda presente em 'nosso' imaginário coletivo e reconstruindo uma verdadeira história positiva capaz de resgatar sua plena humanidade e autoestima destruída pela ideologia racista presente na historiografia colonial. 
Verificamos a importância do estudo da história da população negra de forma clara, sem distorções, em que se oportunize a ela se autoafirmar em seu pertencimento racial nesse contexto de discriminação, em que a autonegação ainda é frequente. Segundo Gomes (2003, p. 171):

Como sujeitos sociais, é no âmbito da cultura e da história que definimos as identidades sociais (todas elas, e não apenas a identidade racial, mas também as identidades de gênero, sexuais, de nacionalidade, de classe, etc.). Essas múltiplas e distintas identidades constituem os sujeitos, na medida em que estes são interpelados a partir de diferentes situações, instituições ou agrupamentos sociais. Reconhecer-se numa delas supõe, portanto, responder afirmativamente a uma interpelação e estabelecer um sentido de pertencimento a um grupo social de referência.

Outro fator que contribui para a construção da identidade negra, segundo a autora, é "[...] a cultura (religiões, artes, medicinas, tecnologias, ciências, educação, visões do mundo, etc.)". Quando é tratada no Brasil a história dos povos que construíram o mesmo, conforme Munanga (2012, p. 1) pontua:

Geralmente, quando se fala dos povos que construíram o Brasil, pensam-se logo em colonizadores portugueses, imigrantes italianos, alemães, espanhóis, árabes, sirio-libaneses, orientais (em especial os japoneses), etc. No imaginário coletivo, acreditase que os africanos foram trazidos aqui depois de sua captura, apenas como primitivos que chegaram 'nus' acorrentados e, como todos os primitivos, não trouxeram nada ao Brasil que importasse para ser considerado como uma contribuição digna de nome. No entanto, os aportes culturais africanos fazem parte do cotidiano de todos os brasileiros: culinário, artes musicais, visuais, religiões populares, breve, estão presentes na maneira de ser brasileiro e brasileira. De fato, a cultura brasileira no plural e sua identidade nacional foram modeladas pelos aportes da população negra. Estas contribuições culturais precisam ser resgatadas positivamente, desconstruindo imagens negativas que fizeram delas e substituindo-as pelas novas imagens, positivamente reconstruídas.

Por fim, sobre o fator psicológico que contribui para a construção da identidade, destaca Munanga (2012, p. 11): 
Mas neste caso, devemos perguntar-nos se existe um temperamento do negro diferente do temperamento do branco que podemos considerar como característica de sua identidade. Tal diferença se for comprovada, deveria ser explicada a partir notadamente do condicionamento histórico do negro dentro da estrutura sociopolítica assimétrica, e também de acordo com suas estruturas sociais comunitárias, e não com bases nas diferenças biológicas, como pensaram os racialistas e racistas ocidentais.

A crença de que a população branca é superior à população negra é muito presente na nossa sociedade, o que faz com que se menospreze a capacidade intelectual do negro em todos os setores, e na universidade não é diferente. Nesse sentido, faz-se necessário que a universidade não apenas se preocupe com a promoção do acesso, mas que também desenvolva ações que contribuam para o fortalecimento da identidade desses grupos nesse espaço em que a maioria é branca. Cabe ressaltar aqui que as políticas afirmativas que têm contribuído para o acesso da população negra à universidade possibilitam a mudança do perfil dos acadêmicos em vários cursos em que a hegemonia branca prevalece.

Contudo as politicas afirmativas possibilitaram o acesso de negros na universidade, tensionando o espaço que muito tempo foi hegemonicamente branco. Corpos negros de homens e mulheres, ainda que não representem proporcionalmente o percentual da população de pretos e pardos presentes na sociedade, circulam pelo campus, com sua alegria, com sua cor, com seu sorriso largo e voz fortes, o que sem dúvida causou fissuras na estrutura eurocêntrica da cultura universitária.

\section{O Acesso de Negros à Educação Superior}

A partir do ensino médio, há uma desigualdade acentuada na frequência entre brancos e negros, ou seja, os jovens negros se evadem ou são reprovados no ensino médio e não são inseridos na educação superior na mesma proporção que os brancos, conforme mostra o gráfico 1 a seguir. 


\section{Gráfico 1 - Distribuição dos brasileiros de 15 a 24 anos de idade que frequentavam a escola por raça ou cor, segundo o nivel de ensino (\%)}

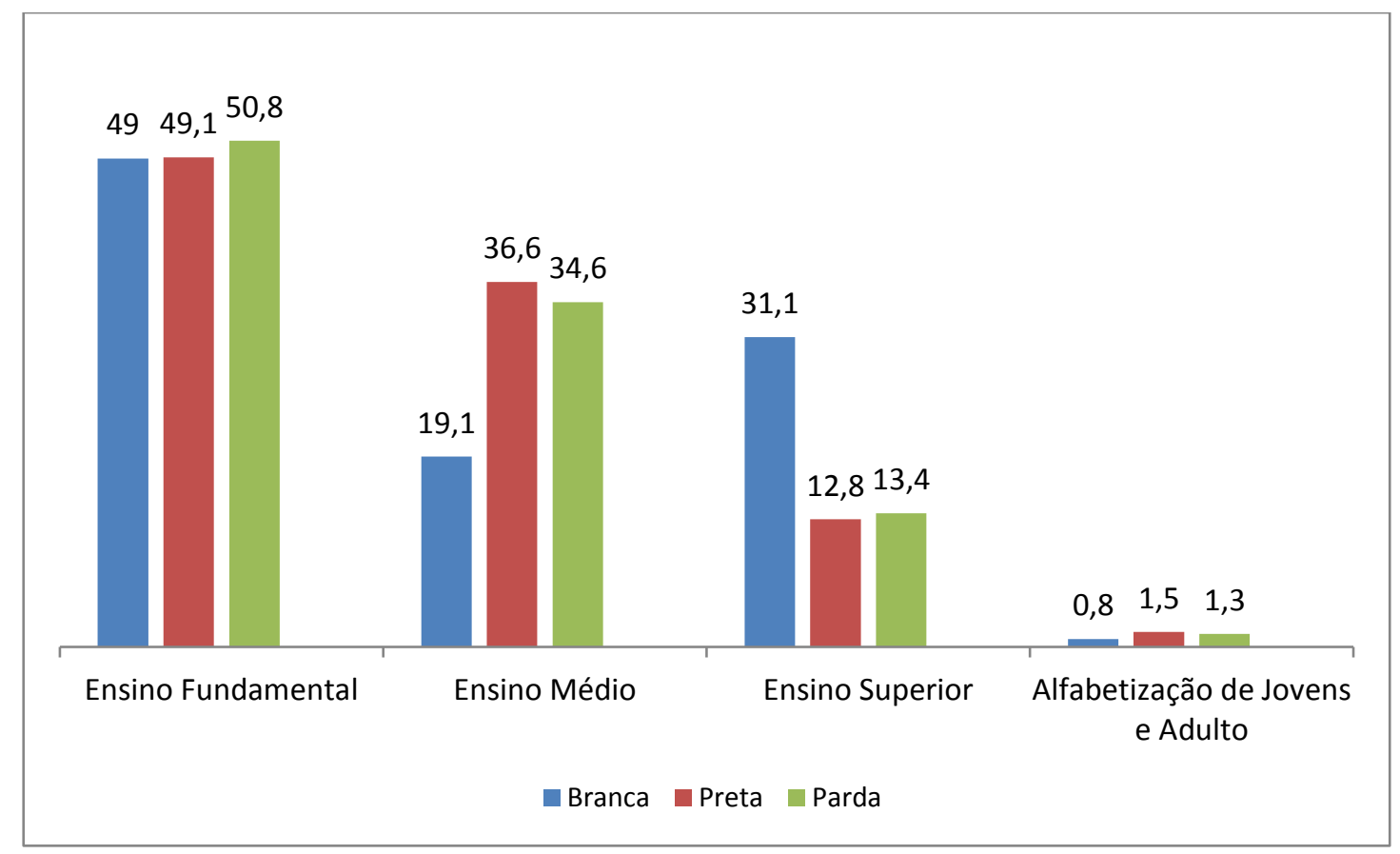

Fonte: IBGE. Censo demográfico 2010.

Nesse sentido, as politicas afirmativas que se efetivam por meio das cotas raciais representam uma estratégia de acesso dessa população que, embora seja a maioria na sociedade, está sub-representada na educação superior. Analisando os dados, nota-se que ocorreram mudanças significativas, porém sabemos que, pelo histórico da população negra no Brasil, há um caminho extenso a percorrer para se chegar a uma igualdade de fato. De acordo com Daflon e Feres (2013, p. 41) "as políticas de ação afirmativa, particularmente as de recorte étnico-racial, têm tido um papel fundamental nessa grande mudança, tanto no plano prático como no simbólico".

Sendo assim, embora existam avanços, há muito que ser feito para se alcançar de fato a igualdade no Brasil, marcado historicamente pela desigualdade racial e social entre brancos e negros, o que demonstra que o racismo ainda está presente em nossa sociedade. De acordo com Paixão (2010, p. 26): 
O reconhecimento de que tenha ocorrido queda nas desigualdades em alguns indicadores recentes dos grupos de cor ou raça no Brasil não implica que tal movimento tenha ocorrido com uma intensidade suficiente para se poder dizer que as desigualdades entre brancos, de um lado, e pretos \& pardos, de outro, tenham sido superadas ou possam vir a sê-lo em um curto espaço de tempo.

Concordando com o autor, apesar dos avanços se faz necessária a desmitificação da desigualdade em todos os setores da sociedade, trazendo as claras todo o enfretamento que a população negra tem sofrido ao longo da história. Fica visivel que somente a adoção de politicas afirmativas universais não é suficiente para amenizar a desigualdade existente ao longo da história da sociedade brasileira. Por isso o recorte de cotas raciais é tão importante na busca por igualdade de oportunidades para a população negra, visto que as politicas de cunho universalistas com capacidade de inserir toda população negra foram insuficientes em todos os setores, inclusive principalmente em relação à educação superior.

A democratização da educação superior revela que as instituições eram compostas pela classe privilegiada, mas as pressões do Movimento Negro pela inclusão da população negra na educação superior deram origem ao debate sobre as ações afirmativas. Para a efetivação dessas ações, faz-se necessária a intervenção do Estado, uma vez que a este incumbe traçar diretrizes gerais. Do outro lado estão alguns grupos que tiveram seus direitos negados, para os quais existe a urgência de se amenizar tamanha desigualdade.

\section{A Percepção da Discriminação Racial e do Preconceito no Espaço Acadêmico}

O mito da democracia racial, segundo Munanga (2004), Guimarães (2002) e Gomes (2005), disseminou e legitimou a ideia de se pensar uma sociedade de convivência harmoniosa entre brancos, negros e indigenas. Gomes (2005, p.57) destaca que o mito se configura como uma corrente ideológica que pretende negar "a desigualdade racial entre brancos e negros no Brasil como fruto do racismo, afirmando que existe entre estes dois grupos raciais uma situação de igualdade de oportunidades e de tratamento". Isso 
gera a perpetuação de estereótipos sobre os negros e a negação do racismo no Brasil e, simultaneamente, reforça a discriminação e a desigualdade raciais. Ou ainda, conforme pontua Munanga (2004, p. 89),

[...] exalta a ideia de convivência harmoniosa entre os indivíduos [...] permitindo às elites dominantes dissimular as desigualdades e impedindo os membros das comunidades não brancas de terem consciência dos mecanismos de exclusão da qual são vítimas na sociedade.

Para a afirmação da identidade negra, esse mecanismo é extremamente perverso e ardiloso, pois leva o indivíduo a acreditar na possibilidade de igualdade e reproduzir esse discurso, podendo até mesmo negar seu pertencimento étnico-racial e não perceber atitudes diretas de discriminação.

Identificamos, nas falas dos acadêmicos entrevistados, situações em que a discriminação e o preconceito racial se materializam direta ou indiretamente,

Fui discriminado mais de uma vez. A mais marcante ocasião foi um dia em que fui de bicicleta para a universidade. Chegando ao bloco, o segurança ordenou que eu descesse da bicicleta porque era perigoso, isso de forma bem grosseira. Eu ia assistir a uma aula no sábado de manhã e só havia alunos da minha turma no local, então eu não via perigo ali. Acho que ele agiu assim de certa forma por questões de preconceito, pois na hora percebi que ele era um segurança bem alto e branco. [...] Foi um ato de discriminação. Imagine você, numa Universidade Federal, uma pessoa negra chega de bicicleta; imagine o olhar daquele segurança para mim. (Andrey).

Esse relato nos remete ao que Nogueira (1985, p. 79) denominou de preconceito de marca, quando se exerce em relação à aparência, isto é, "quando toma por pretexto para as suas manifestações, os traços físicos do indivíduo, a fisionomia, os gestos, o sotaque”. Marques, Almeida e Silva (2014, p. 55-56) sinalizam que no Brasil, tanto o preconceito quanto a discriminação racial produzem "[...] efeitos perversos na vida da população negra, os quais se manifestam desde a vida familiar, na infância, na adolescência, até a esfera da sociedade politica, na educação e no trabalho".

Constatamos, nos depoimentos, a discriminação sofrida pelos acadêmicos negros, seja direta ou indiretamente. Muitas vezes a discriminado 
se dá pelo seu fenótipo, o que causa constrangimentos e influência a afirmação de sua identidade. Destacamos ainda que a maioria das respostas dadas ao questionário online relata essa discriminação presente nas "brincadeiras" ou comentários registrados nas questões do tipo: Você foi discriminado na Universidade devido ao seu pertencimento racial?

Você é espertinho, tem jeito de branco aqui na faculdade.

E se não fosse a Dilma dar as cotas, onde você estaria?

Já agradeceu à Dilma hoje?

Cada coisa que se vê! Cotas para quem não sabe nada.

Sim, já me chamaram de cabelo duro.

Sim, fui chamado de cabelo pixaim.

As falas dos acadêmicos retratam, além do preconceito, a defesa da meritocracia e a certeza de que a universidade não é espaço para os negros ingressantes pelas cotas, além de ignorarem o significado das políticas afirmativas iniciadas no governo de FHC. Reproduzem a ideia de que são políticas partidárias e ignoram o sentido de constitucionalidade. Conforme ilustra Gomes (2003, p. 3),

[...] a identidade negra é entendida como um processo construído historicamente em uma sociedade que padece de um racismo ambíguo e do mito da democracia racial. Como qualquer processo identitário, ela se constrói no contato com o outro, no contraste com o outro, na negociação, na troca, no conflito e no diálogo.

Percebe-se, pois, que a discriminação se manifesta de diversas formas, como pontua Marques (2010), “[...] a discriminação racial pode se manifestar de diferentes modos e graus, desde os apelidos e piadas que tendem a inferiorizar o outro, até a ofensa física". Com a presença do negro no espaço acadêmico, em que a hegemonia branca predominou e predomina, a universidade precisa propor ações no sentido de propor debates e discussões sobre as politicas afirmativas. Ressaltamos que o REUNI proporcionou algumas mudanças positivas em relação à criação de algumas disciplinas, conforme o acadêmico Andrey relata: 
O fator que contribuiu foi a busca da afirmação da minha identidade. Assim que eu comecei a estudar, tive disciplinas referentes aos Direitos Humanos e Relações Étnico-Raciais, e ali me encontrei. Eu via a minha história naquelas disciplinas e esse foi o fator que me instigou a permanecer. Outro fator que me instigou a permanecer foi a realização de um sonho: provar para mim mesmo que uma pessoa negra pode entrar na Universidade, permanecer e concluir um curso. Hoje estou concluindo, praticamente já terminei e me sinto muito melhor com a minha vida, com a minha identidade e por não ter desistido no meio do caminho. Também encontrei a professora Eugênia, que ministrou a disciplina que me instigou a buscar essa afirmação de identidade e ver que eu não estava sozinho. Ela me fez perceber que eu poderia contribuir também com outras pessoas na afirmação de sua identidade e na quebra de alguns preconceitos. Isso para mim foi fundamental. Também me instigou a participação nos eventos do NEAB e no grupo GEPRAFE. Eu coloco a professora Eugênia como uma das pessoas responsáveis pela minha permanência na Universidade, ela me ajudou muito (Andrey). (Grifos nossos).

Evidenciamos então a necessidade que o acadêmico tem de se encontrar nesse ambiente universitário. Conforme Santos (2009, p. 159), é importante que ele se sinta parte daquele novo espaço, pois se trata de sua identificação com os demais universitários e da aquisição de uma cultura universitária. Observamos que somente o acesso à educação superior não é garantia de fortalecimento da identidade negra, e que os acadêmicos ingressantes pelas cotas não irão se sentir tranquilos para se manifestarem num ambiente tão hostil e excludente. Conforme pontua Munanga (2004, p. 16):

O ideal (de branqueamento) inculcado através de mecanismos psicológicos ficou intacto no inconsciente brasileiro, rodando sempre na cabeça dos negros e mestiços. Esse ideal prejudica qualquer busca baseada na "negritude", já que todos sonham ingressar um dia na identidade branca, por a julgarem superior.

Verifica-se ainda que os acadêmicos negros cotistas sofrem dupla discriminação no espaço acadêmico: por serem cotistas e por serem negros. Em algumas situações, também pelo fato de serem discriminados por meio de brincadeiras preconceituosas. 


\section{Considerações Finais}

Reconhecemos que o Movimento Negro foi um elemento imprescindível no processo de reivindicar os direitos e de pressionar os governos para que adotassem politicas públicas de promoção da igualdade racial. Nascimento (2007) sinaliza que a pressão do Movimento Negro, por meio de denúncias das desigualdades, concretizou as politicas afirmativas; as cotas raciais são exemplo dessas conquistas que garantiram o acesso da população negra à educação superior, transformando o espaço acadêmico das universidades do Brasil.

Compreendemos, pois, que se faz necessário levar em consideração os diferentes elementos que influenciam na construção e no fortalecimento da identidade desse sujeito sociável, mostrando-lhe o significado de pertencimento a um grupo ou a uma cultura. Concordamos com Hall (2006, p. 8), que define a identidade cultural como “[...] aqueles aspectos de nossas identidades que surgem de nosso "pertencimento" a culturas étnicas, raciais, linguísticas, religiosas e, acima de tudo, nacionais".

Com relação ao fortalecimento da identidade negra, percebemos que é muito difícil ter uma identidade fortalecida quando a cultura eurocêntrica é a predominante em todos os setores; quando tudo que não se assemelha ao seu padrão é discriminado. De acordo com Gomes (2003), não é fácil construir uma identidade positiva numa sociedade que ensina o negro a negar a si mesmo. Nesse contexto, os dados da pesquisa demonstraram que todas as situações de discriminação e preconceito que estão presentes na sociedade brasileira, constantemente denunciadas pelo Movimento Negro e pela sociedade civil, estão presentes no espaço acadêmico.

É perverso e doloroso para esses sujeitos terem que passar por situações de discriminação, ser ignorados e desumanizados como sujeitos de direitos que deveriam ser considerados e não o são. A discriminação, de forma direta ou indireta, ofende e humilha, conforme esta dirigida a um acadêmico entrevistado: “Já agradeceu a Dilma hoje?”. Pode até parecer que o tom foi de brincadeira, mas quem emitiu essa frase sabe exatamente o que quer atingir e como atingir. A discriminação racial pode ser percebida de diversas 
maneiras, e às vezes somos levados a acreditar que ela vem em forma de brincadeiras inocentes, e não consideramos o mal que pode causar à pessoa que a recebe.

Marques (2010, p. 224) pontua que os negros enfrentam, desde a infância, "o desafio de construir a sua identidade num universo permeado de ideologias racistas, que hierarquizam as pessoas pela cor de sua pele (preconceito de marca), ainda presente na sociedade brasileira".

Também é importante salientar que o fortalecimento da identidade negra se dá em meio a muitas tensões, principalmente numa sociedade que, segundo Gomes (2005), em que o negro é ensinado a negar a si mesmo. Inferimos a necessidade de a universidade ser um espaço em que aconteçam as tensões, porém que aconteça também o fortalecimento da identidade de seus acadêmicos por meio do empenho de todos que ali inseridos se encontram.

\section{Referências Bibliográficas}

AZIBEIRO, Nadir Esperança. Educação intercultural e complexidade: desafios emergentes a partir das relações em comunidades populares. In: FLEURI, Reinaldo Matias (Org.). Educação intercultural: mediações necessárias. Rio de Janeiro, RJ: DP\&A, 2003.

CARNEIRO, Maria Luiza Tucci. O racismo na história do Brasil: mito e realidade. 2. ed. São Paulo, SP: Ática, 1995.

DAFLON, Veronica Toste; FERES JÚNIOR, João. Políticas da igualdade racial no ensino superior. Cadernos do Desenvolvimento Fluminense, n. 5, 2013.

DAYRELL, Juarez. A escola como espaço sócio-cultural. In: DAYRELL, J. (Org.). Múltiplos olhares sobre a educação e cultura. Belo Horizonte, MG: UFMG, 1996.

GOMES, Nilma Lino. Educação, identidade negra e formação de professores/as: um olhar sobre o corpo negro e o cabelo crespo. Revista Educação e Pesquisa, São Paulo, v. 29, n. 1, p. 167-182, jan./jun., 2003.

- Alguns termos e conceitos presentes no debate sobre relações raciais no Brasil: uma breve discussão. In: EDUCAÇÃO Anti-racista: caminhos abertos pela Lei Federal no 10.639/03. Brasília, DF: MEC, Secretaria de educação continuada e alfabetização e diversidade, 2005. p. 39-62. 
GOMES, Nilma Lino. Trajetórias escolares, corpo negro e cabelo crespo: reprodução de estereótipos ou ressignificação cultural? Revista Brasileira de Educação, no 21, p. 40-51, set./dez., 2002.

GUIMARÃES. Antônio Sérgio. Classes, raças e democracia. São Paulo, SP: Fundação de Apoio à Universidade de São Paulo: Editora 34, 2002.

GUSMÃO, Neusa Maria Mendes. Os desafios da diversidade na escola. In: GUSMÃO, Neusa Maria Mendes. (Org.). Diversidade, cultura e educação: olhares cruzados. São Paulo, SP: Biruta, 2003.

HALL, Stuart. A identidade cultural na pós-modernidade. Trad. Tomaz T. da Silva G. Lopes Louro. Rio de Janeiro, RJ: DP\&A, 2006.

JACCOUD, Luciana; BEGHIN, Nathalie. Desigualdades raciais no Brasil: um balanço da intervenção governamental. Brasília, DF: IPEA, 2002.

MARQUES, Eugenia Portela de Siqueira. O Programa Universidade para Todos e a inserção de negros na educação superior: a experiencia de duas Instituições de Educação Superior de Mato Grosso do Sul - 2005-2008. Tese (Doutorado em Educação) - Universidade Federal de São Carlos, 2010.

MARQUES, Eugenia Portela de Siqueira; ALMEIDA, Fernanda Alexandrina de; SILVA, Wilker Solidade. A percepção do preconceito e da discriminação racial no ambiente escolar. Interfaces da Educação, Paranaíba, v.5, 2014.

MIGNOLO, Walter. Histórias globais/projetos locais: colonialidade, saberes subalternos e pensamento liminar. Belo Horizonte, MG: UFMG, 2003.

MUNANGA, Kabengele. Estratégias e poéticas de combate à discriminação Racial. São Paulo, SP: Edusp/Estação Ciência, 2004.

Negritude e identidade negra ou afrodescendente: um racismo ao avesso? Revista da ABPN, v. 4, n. 8, jul./out., p. 6-14, 2012.

. Identidade, cidadania e democracia: algumas reflexões sobre os discursos anti-racistas no Brasil. In: SPINK, Mary Jane Paris (Org.) A cidadania em construção: uma reflexão transdisciplinar. São Paulo, SP: Cortez, 1994, p. 177-187.

NASCIMENTO, Alexandre do. Das ações afirmativas dos movimentos sociais às políticas públicas de ação afirmativa: O movimento dos cursos prévestibulares populares. In: II SEMINÁRIO NACIONAL - MOVIMENTOS SOCIAIS, PARTICIPAÇÃO E DEMOCRACIA. Anais... Florianópolis: UFSC, 25 a 27 de abril de 2007. Disponivel em: <http://www.sociologia.ufsc.br/npms/alexandre_do_nascimento.pdf $>$. Acesso em: 14 mar. 2017. 
NOGUEIRA, Oracy. Preconceito racial de marca e preconceito racial de origem. Sugestão de um quadro de referência para a interpretação do material sobre relações raciais no Brasil Tempo Social. Revista de sociologia da USP, v. 19, n. 1, 2006.

QUIJANO, Anibal. Colonialidade do poder, eurocentrismo e América Latina. En libro: a colonialidade do saber: eurocentrismo e ciências sociais.

Perspectivas latino-americanas. Edgardo Lander (Org.). ColecciónSurSur, CLACSO, Ciudad Autónoma de Buenos Aires, Argentina, setembro p. 227278, 2005. Disponivel em:

<http:/ / bibliotecavirtual.clacso.org.ar/ar/libros/lander/pt/Quijano.rtf>. Acesso em: 20 abr. 2017

PAIXÃO, Marcelo; ROSSETO, Irene, MONTOVANELE, Fabiana; CARVANO, Luiz M. "Introdução". In: (Org.). Relatório Anual das Desigualdades Raciais no Brasil: 2009-2010. Constituição cidadã, seguridade social e seus efeitos sobre as assimétricas de cor ou raça. Rio de Janeiro, RJ: Garamond. Disponivel em: <http://www.novo.afrobras.org.br>. Acesso em: 15 maio 2017.

SANTANA, Renato Oliveira. Efeitos da educação superior nas identidades de negros cotistas da Universidade Estadual de Mato Grosso do Sul, 2010. Disponivel em:

<http:/ / www3.ucdb.br/mestrados/arquivos/dissert/742.pdf>. Acesso em: 21 jun. 2017.

SANTOS, Gevanilda; SILVA, Maria Palmira dos. Racismo no Brasil: percepções das discriminações e do preconceito no século XXI. São Paulo, SP: Editora Fundação Perseu Abramo, 2005.

SANTOS, Dayane Brito Reis. Para além das cotas: a permanência de estudantes negros no ensino superior como politica afirmativa. Tese (Doutorado em Educação) - Universidade Federal da Bahia (UFBA), Salvador, Bahia, 2009.

Recebido: 16 de agosto de 2017

Aceito: 10 de setembro de 2017

Publicado: 19 de setembro de 2017 